have important implications in regard to other noxious substances at the present time readily available. Such difficulties should not dissuade the authorities from considering paraquat as a particular case. One could well argue that these other substances have not been involved in such serious poisonings as paraquat itself despite being under no greater restriction. This may well be in part because they are less toxic and more amenable to known forms of therapy.

I have personally been concerned for some time about the apparent ineffectiveness of controls over the use and distribution of paraquat. My action in writing this letter was precipitated by two very recent but unrelated instances of children being accidentally poisoned by paraquat in the Edinburgh area.

At the present time our community is being exhorted to care more about the quality of its life and its environment. I would make a plea to the medical profession to support a ban on the use of this highly dangerous weedkiller as I feel that this would be an important contribution in the field of preventive medicine.-I am, etc.,

\section{Milesmark Hospital,}

A. A. H. LAwson Dunfermline

\section{Accidental Vaccination with Paraquat}

SIR,-A man aged 30 used Gramoxone (which contains paraquat) to spray weeds near an orchard. He was wearing shorts and recalls being scratched lightly on the legs by the spines on the stems of Galium aparine (goosegrass) as he worked. He is uncertain when next he washed his legs but certainly had a bath within 24 hours.

He presented six days after exposure, by which time he had developed 10 to 12 lesions above and below both knees. They were linear, $6-12 \mathrm{~mm}$ wide and $5-15 \mathrm{~cm}$ long, running in various directions, slightly raised, red brown in colour and itching. Vesiculation was occurring at three intersections and developed to resemble a primary vaccination. There were no systemic symptoms. The urine paraquat level determined on the seventh day was less than $0.01 \mu \mathrm{g} / \mathrm{ml}$. The lesions, dressed twice daily with Dequadin Tulle, resolved in 14-21 days, though marks were visible for some time afterwards. There were no sequelae.

Although the patient in this case suffered no more than discomfort and inconvenience, this report underlines the necessity of following the maker's instructions for the use of the spray, which specifies that protective clothing should be used.-I am, etc.,

Warrington

P. J. BARBER

\section{Treatment of Acute Poisoning}

SIR,-Dr. H. Matthew's recent contribution on "Acute Poisoning" (6 March, p. 519) is a most helpful refutation of myth-information. Only one point would warrant any serious disagreement: his championing of gastric lavage versus induction of emesis. Certainly neither approach can be viewed as any panacea. In Dr. Matthew's own experience ${ }^{1}$ in only $17 \%$ of 165 patients suffering barbiturate poisoning was more than $200 \mathrm{mg}$ of barbiturate actually recovered from the gastric washings. While emesis certainly is contraindicated in the instance of the drowsy or unconscious patient, and though its returns may not be sizeable either, attention should be directed to the studies of Boxer, Anderson, and Rowe. ${ }^{2}$ Responsible for treating large numbers of accidental ingestions, these authors assigned their paediatric patients (all salicylate ingestors) to one of two treatment groups. One group was treated by lavage which, upon completion, was followed immediately by induction of emesis. For the other group, the sequence of treatments was reversed. All stomach contents were saved and analysed for salicylates. Notably, when emesis followed lavage it led to recovery of twice as much salicylate as had lavage itself. In contrast, where lavage followed emesis, it resulted in augmenting recovery by less than $10 \%$ of the amount of salicylate originally removed by emesis.

Only last June, Goldstein ${ }^{3}$ cited two testimonial cases of purposeful ingestion by young adults in whom "adequate" lavage had been originally carried out with minimal return. Subsequent induction of emesis brought forth 25 tablets from one and at least 10-15 from the other.

Conceivably the future may see a resurgence of activated charcoal and its adsorptive qualities replace both of the forementioned approaches. Until that time, induction of emesis would seem to be warranted in many instances-particularly for children. Syrup of ipecac. or apomorphine are appropriate emetics. A plea is made, however, not to employ salt as an emetic agent. Four disasters following such an approach already have come to this writer's attention.-I am, etc.,

\section{Poisons Control Center,}

Poisons Control Center, Seattle, Washington, U.S.A.

1 Matthew, H., Mackintosh, T. F., Tompsett, S. L., and Cameron, J. C., British Medical fournal, 1966, 1, 1333. Boxer. L., Anderson, F. P., and Rowe, D. S.,
fournal of Pediatrics, 1969, 74, 800 .

Association, 1969, 208, 2162.
Astein, L. I., Fournal of the

\section{Fats and Multiple Sclerosis}

SIR,-In your leading article entitled "Fats and Multiple Sclerosis" (5 June, p. 545) you discuss the possible suggestion of $R$. L. Swank that the high incidence of multiple sclerosis in some parts of the world can be related to dietary habits, and that in those areas diets generally tend to be rich in saturated fatty acids. Following this suggestion, he has suggested that modification of the diet for patients with multiple sclerosis in such a way as to reduce their intake of total fat and include a great proportion of unsaturated fatty acids will improve the patient's functional condition and reduce the relapse rate.

Against this very interesting theory are the established facts that the incidence and prevalence of multiple sclerosis among the two and a half million Afrikaans-speaking white population of South Africa is very low, only one-eleventh of the prevalence that occurs in immigrants from Britain and Northern Europe. ${ }^{1}$ The English-speaking white South African-born have only one-fourth of the risk of the immigrants. White South Africans, particularly the Afrikaans-speaking, eat a diet that is particularly rich in saturated fatty acids. They often have fatty meat, such as bacon or mutton, as much as three times a day. Death from ischaemic heart disease, coronary thrombosis, is very high among white South Africans and is particularly high among males below the age of 65 , many of whom have a raised cholesterol. ${ }^{2}$

The high animal fat consumption and high morbidity and mortality from ischaemic heart disease among the white South African-born, particularly the Afrikaner, is in direct contrast to their low risk of developing multiple sclerosis and does suggest that a high fat diet cannot be the environmental factor that is responsible for this disease, although the epidemiological evidence does show conclusively that it is primarily a disease of the environment. The South African situation does not exclude the possibility that diet may be an additional factor, but it is certainly not the most important one, and the present epidemiological evidence suggests very strongly that multiple sclerosis is more likely to be caused by a virus infection of the central nervous system. $.^{3}-\mathrm{I}$ am, etc.,

Medico-Social Research Board,

Geoffrey DeAN Dublin 1 Dean, G., British Medical fournal, 1967, 2, 724. 39, July Suppl., p. 1 . 3 Dean, G., Scientific American, 1970, 223, 40.

\section{Aspirin Allergy}

SIR,-I felt really surprised when I read, in relation to aspirin allergy, in Dr. A. P. Smith's article "Response of Aspirin-allergic Patients to Challenge by Some Analgesics in Common Use" (29 May, p. 494) " . . and lymphocyte transformation tests have been negative".

In our laboratory of the Institut d'Immuno-Biologie, Hôpital Broussais, we have been testing more than 300 patients with aspirin allergy, and when the clinical history had been taken properly, and, what is very important, the patient was not taking any corticosteroids for more than three weeks, lymphoblastic transformation tests were regularly positive.

First results were presented at the Société Française d'Allergie ${ }^{1}$ in February 1967. Further results have been presented and discussed widely recently at the 7th International Congress of Allergology in Florence.

We believe that sometimes intolerance to acpirin may occur, but when a patient is suffering from the "triple syndrome" with late and infectious asthma, nasal polyps, and allergy to aspirin, a lymphoblastic transformation test should be performed, if the patient can breathe for three weeks without any corticosteroids or immunosuppressive drugs.-I am, etc.

Paris $\quad$ Editor, Allergie et Immunologie

1 Halpern, B. N., Ky, N. T., Hazard, J., Amache, N., and Lagrue, G., Revue Française d' Allergie,

\section{Aortic Aneurysm and Peptic Ulcer}

SIR,-We read with interest your leading article on the association of peptic ulceration with abdominal aortic aneurysm (16 January, p. 129). We recently noted a similar link between peptic ulceration and occlusive arterial disease of the lower limbs. 